\title{
As dinâmicas nas políticas de ensino superior - um modelo teórico
}

\author{
Dynamics in higher education politics: a theoretical model
}

http://dx.doi.org/10.5007/2178-4582.2016v50n1p241

\author{
Jaakko Kauko \\ University of Helsinki, Helsinki, Finland
}

\begin{abstract}
Este artigo apresenta um modelo para analisar as dinâmicas nas políticas de ensino superior (DHEP). Teoricamente, o modelo baseia-se na história conceitual da contingência política, das teorias do agendamento (agenda setting) e em pesquisas anteriores sobre o assunto. De acordo com o modelo, a complexidade sócio-histórica pode ser melhor analisada considerando-se duas dimensões: a situação política e as possibilidades políticas. Empiricamente, o modelo foi testado e desenvolvido no contexto do ensino superior finlandês, por meio de entrevistas e de material documental, cujos resultados tornaram possível identificar que as dinâmicas nas políticas de ensino superior estão fortemente relacionadas a mudanças externas ao sistema de ensino superior, posições mutáveis dos atores em diferentes vertentes políticas e à natureza inesperada das dinâmicas. As DHEP também podem ser usadas para desvelar os efeitos das possibilidades estabelecidas, porém implícitas, que podem viabilizar ou impossibilitar outras vertentes políticas em um sistema de ensino superior.
\end{abstract}

Palavras-chave: Dinâmicas; Políticas de Ensino Superior; Contingência; Agendamento;
This article presents a model for analyzing $d y$ namics in higher education politics (DHEP). Theoretically, the model draws on the conceptual history of political contingency, agenda-setting theories and previous research on higher education dynamics. According to the model, socio-historical complexity can best be analyzed along two dimensions: the political situation and political possibilities. On the empirical level, the model has been tested and developed in the context of Finnish higher education by means of interviews and documentary material. It appears from the empirical findings that dynamics in higher education politics are strongly related to changes that are external to the higher education system, the changing positions of the actors in different policy threads and the unexpected nature of the dynamics. The DHEP can also be used to shed light on the effects of the silent, settled possibilities that may enable or disable other policy threads within a higher education system.

Keywords: Dynamics; Higher Education Politics; Contingency; Agenda setting.

\section{Introdução}

Pesquisas anteriores relacionadas ao ensino superior reconhecem a falta de teorização sobre a questão política como um todo e a tendência de concentração em uma única política (METCALFE, 2008; SLAUGHTER; RHOADES, 2005; BAUMGARTNER, GREEN-PEDERSEN; JONES, 2006). Além disso, as abordagens são particularmente polarizadas. Uma análise de três influentes periódicos do ensino superior revela a predominância de uma abordagem estrutural mais ou menos descritiva e heurística, enquanto o ator, a agência e outras perspectivas permanecem, de certa forma, nas sombras (URSIN; SAARINEN, 2012). Uma fonte óbvia de novas teorias seria a ciência política, mas, surpreendentemente, ela quase nunca é mencionada (FERLIE; MUSSELIN ANDRESANI, 2008). Assim, este parece ser um momento oportuno para desbravar no- 
vos caminhos para a pesquisa. Neste artigo ${ }^{1}$, descrevo um modelo para analisar as dinâmicas nas políticas de ensino superior (DHEP) que se fundamenta em pesquisas anteriores sobre ciência política e dinâmicas neste campo.

O principal foco das DHEP está nos atributos das relações e não dos atores. A ênfase nessas inter-relações ou nas dinâmicas não é uma abordagem comum. Grande parte da investigação na área de ciências sociais, e também dos sistemas de ensino superior, inicia-se com uma análise dos interesses ou características distintas de diferentes atores. Estes são pontos informativos e bem estabelecidos de análise. Mas, a partir da perspectiva das inter-relações, eles incorporam pressuposições de características relativamente estáveis em diferentes indivíduos (EMIRBAYER, 1997) e uma visão estática da política (PALONEN, 2007). Muitos estudiosos do ensino superior estão cientes desse problema.

Em termos mais práticos, instituições do sistema de ensino superior têm importância variável em diferentes reformas e há pontos de vista diversos sobre sua importância (OLSEN, 2007; VÄLIMAA, 2005). Existe uma infinidade de histórias relacionadas a processos de política única e "diferentes grupos interpretam políticas de maneiras diferentes" (MILLS, 2007, p. 185). Em última instância e, paradoxalmente, em termos de interesses, os formuladores de políticas podem tomar decisões dissonantes em diferentes contextos (KAUKO, 2011). Por esta razão, a ênfase nas dinâmicas poderia favorecer uma compreensão mais profunda das complexidades do mundo.

Algumas das pesquisas básicas no campo do ensino superior possuem duplo enfoque, enfatizando tanto os atributos dos atores quanto das relações, como por exemplo a ideia de selecionar as principais partes interessadas (corpo acadêmico, Estado ou estudantes) ou lógicas operacionais (mercado ou gerencial) e compará-las para produzir uma descrição empiricamente derivada do sistema de ensino superior é comum ao triângulo de Clark e suas adições anteriores (NEAVE, 1992; FRACKMANN, 1992), e mais recentes (BOER, ENDERS; SCHIMANCK, 2007). No entanto, críticos como Ferlie, Musselin e Andresani (2008) apontam que a ênfase de Clark na relação estado-universidade ignora muitas outras instituições, enquanto Kogan e Hanney (2000) questionam o pressuposto de que a natureza especial das universidades define o resto do sistema (apud FRACKMANN, 1992). Em outras palavras, com

\footnotetext{
1 Esta pesquisa é parte do projeto Power, Supranational Regimes and New University Management (Poder, Regimes Supranacionais e a nova Gestão da Universidade), financiado pelo projeto Power and Society (Poder e Sociedade) da Academy of Finland (2007-2010), liderado por Risto Rinne (Universidade de Turku) e Hannu Simola (Universidade de Helsinque). Sou grato a eles pelo apoio à minha tese e aos colegas e amigos de quem tive a sorte de receber ajuda (vide KAUKO, 2011). Também gostaria de agradecer a Wieland Wermke e aos revisores anônimos que me ajudaram a articular e desenvolver melhor minhas ideias neste artigo. Copyright com a devida permissão de Springer Science+Business Media.
} 
muita frequência as ideias das pesquisas nos fazem encarar as universidades e seus interesses como um ponto de referência para todo o sistema.

$\mathrm{O}$ enfoque nas universidades também causa dificuldades na definição de interesses. Olsen (2007), por exemplo, faz uma distinção, aplicável neste caso, considerando a possibilidade de uma universidade ser regida por fatores internos ou ambientais e dos atores manifestarem normas e objetivos compartilhados ou conflitantes (SAARINEN; VÄLIMAA, 2006; SAARINEN, 2007). Contudo, qualquer divisão entre as agendas interna e externa precisaria de uma definição dos interesses da universidade e suas partes interessadas (stakeholders). A discussão sobre governança interna e externa também pode levar à dicotomia inerente a modelos top-down e bottom-up (CERYCH; SABATIER, 1986; SABATIER, 2005). Cerych e Sabatier, por exemplo, se depararam com o problema da complexidade ao adotar esta perspectiva para análise das reformas e seu sucesso ou fracasso. Atentar para a interação e seus resultados poderia evitar a incômoda questão de interesses. Além disso, um enfoque equivalente em todas as instituições do sistema de ensino superior poderia oferecer uma perspectiva mais ampla.

Levando-se em consideração a crítica de pesquisas anteriores, o modelo das DHEP concentra-se em diferentes instituições de um sistema de ensino superior e suas relações. Acredita-se que as instituições controlam o comportamento das pessoas que a frequentam por meio de regulamentos formais, normas sociais ou interpretações da realidade, dependendo da tradição de pesquisa (SCOTT, 2008). Elas também são definidas, em um sentido amplo, como atores por si só, e como ministérios, universidades, sindicatos, entidades financiadoras, instituições políticas abrangentes e também - o que é mais heterodoxo - partes interessadas da universidade, como organizações de interesse, stakeholders (MAYNTZ; SCHARPF, 1995). O modelo representa uma macro-abordagem ao retratar as instituições como atores principais dentro de um sistema de ensino superior, embora também leve em consideração os empreendedores políticos (policy entrepreneurs) como atores individuais. A seguir, descrevo o modelo, inspirado em teorias de ciência política, e testo-o empiricamente no contexto do ensino superior finlandês.

\section{Teorização das dinâmicas no contexto de contingência}

Embora já existam pesquisas sobre as dinâmicas no ensino superior, ainda não há nenhuma estrutura teórica que facilite a sua análise. Isso motivou meu interesse no desenvolvimento de um modelo para analisar as dinâmicas nas políticas de ensino superior (DHEP). Antes de abordar a pesquisa propriamente dita, devo esclarecer dois pontos sobre a formação do modelo. 
Em primeiro lugar, os termos referencial (framework), teoria e modelo são usados às vezes como sinônimos, mas neste artigo sigo Ostrom (2005), que os compreende de forma integrada: um referencial identifica os elementos essenciais da pesquisa, a teoria concentra-se neste ponto de vista e o modelo teórico auxilia na elaboração de suposições precisas. O referencial teórico das DHEP foi desenvolvido com base na história conceitual da contingência política e em pesquisas anteriores sobre as dinâmicas no ensino superior. Assim, é possível concentrar-se em duas dimensões de contingência. As teorias desta perspectiva relacionam-se com o agendamento (agenda setting), e são especialmente úteis na identificação de interpretações adicionais dessas duas dimensões. Quando conectadas aos resultados empíricos, as ideias teóricas possibilitam a construção de um modelo mais preciso.

Em segundo lugar, os esforços empíricos e teóricos têm avançado paralelamente na prática e o processo está longe de ser linear. Na construção do modelo teórico, baseio-me no trabalho empírico e teórico realizado em conjunto com um projeto de pesquisa no contexto da política de ensino superior na Finlândia (KAUKO, 2011). Realizei2 e analisei 25 entrevistas com políticos no nível ministerial, funcionários do alto escalão do ministério, reitores de universidades e vários representantes dos stakeholders (grupos de interesse, sindicatos dos trabalhadores e financiadores de pesquisa), e examinei, ainda, um conjunto de 132 documentos. Os trabalhos - empírico e teórico - avançaram simultaneamente, mas este artigo concentra-se sobretudo nos aspectos teóricos. Apresento o modelo teórico a seguir, por uma questão de clareza, deixando os resultados empíricos para mais adiante.

Pesquisas anteriores (FERLIE; MUSSELIN; ANDRESANI 2008; GORNITZKA et al., 2007; MEISTER-SCHEYTT; SCHEYTT, 2005; BLEIKLIE, 2000) sobre as dinâmicas no ensino superior concentram-se no todo que compreende as relações entre as instituições em seus quadro temporais e sociais. Estes estudos têm dois aspectos em comum. Em primeiro lugar, existe uma forte ênfase histórica com uma base empírica. As instituições e os atores dos sistemas de ensino superior estão interligados pela história, sendo praticamente impossível fazer uma análise de uma situação complexa sem compreender os desenvolvimentos históricos, pois só uma perspectiva histórica possibilita a identificação de dinâmicas (CLARK, 2008; PIERSON, 2004; BLEIKLIE, 2000; 2006,; KOGAN et al. , 2000, CORBETT, 2005; SCHARPF, 1997). Em segundo lugar, os estudos não endossam a predominância de qualquer agência ou estrutura, mas concentram-se na interação. Considerando-se a agência, estes estudos enfatizam as regularidades e irregularidades na complexidade das inter-relações entre as instituições e os atores. Entretanto, a estrutura também

Hannu Simola e/ou Risto Rinne também estavam realizando as entrevistas em paralelo. 
é importante porque as mudanças no sistema de ensino superior costumam ser iniciadas por impulsos externos (FERLIE; MUSSELIN; ANDRESANI 2008; KOGAN et al., 2000; MAYNTZ; SCHARPF, 1995). Em suma, pode-se dizer que a política é sempre marcada pela contingência. Essa também é a base sobre a qual o referencial teórico das DHEP foi construído.

Em termos mais práticos, de acordo com a abordagem de dinâmicas, a contingência inerente à política faz com que uma reforma seja sempre diferente de seu propósito original, estando fadada ao fracasso. A política é refém de uma combinação de fatores políticos, econômicos e sociais, o que torna impossível acreditar em uma formulação política predeterminada (BLEIKLIE; HØSTAKER; VABO, 2000; VÄLIMAA; HOFFMAN, 2008).

Para explicar mais claramente o que se entende por contingência, refiro-me aos estudos históricos de Palonen (2006), nos quais o autor distingue três agrupamentos conceituais sobre o tema "política": prudência e política; compromisso e contestação; e contingência. Obviamente, o mais interessante para este trabalho é o agrupamento de contingência, com suas dimensões de situação, possibilidade e play \& game. Concentro-me nas duas primeiras dimensões, deixando a terceira para análise posterior (play \& game está mais relacionada com táticas políticas, que transferem o enfoque para o nível individual, enquanto meu enfoque está nas instituições). No plano institucional, a metáfora do jogo (game) poderia estar associada à teoria dos jogos (SCHAR$\mathrm{PF}, 1997)$, mas isso exigiria que os melhores resultados para cada um dos envolvidos estivessem previamente definidos, levando, mais uma vez, aos problemas de definição de interesses. Portanto, para formar o referencial teórico, sugiro que, em termos de sistema, as dinâmicas nas políticas de ensino superior são melhor analisadas quando se consideram estas duas dimensões: situação política e possibilidades políticas.

As duas dimensões mencionadas acima, e os quatro tipos de dinâmicas que elas viabilizam, são descritos no modelo das DHEP retratado na Tabela 1. Em conformidade com a abordagem de dinâmicas, a situação política vincula a análise ao contexto histórico, enquanto as possibilidades políticas revelam as inter-relações entre as instituições. Recorro, agora, a teorias do agendamento (agenda-setting) para uma maior aproximação destas duas dimensões e das quatro dinâmicas a elas relacionadas.

\section{Situações políticas favoráveis e desfavoráveis}

A política como uma situação conota a ideia de um momento oportuno, ou kairos, quando a política pode ser alterada e quando uma ruptura histórica é visível. Para a mudança ocorrer, os atores têm de perceber o kairos ou 
fazer uma reinterpretação radical para criar um momento favorável à mudança (PALONEN, 2006, apud GREEK ANTHOLOGY [1918]). Observei que muitas das teorias do agendamento (agenda setting) que enfatizam a questão histórica reconhecem que o momento oportuno surge quando os fatores internos de um sistema de ensino superior estão em sincronia com os fatores externos. Para tornar a ideia mais concreta, vou analisá-la considerando três teorias diferentes: Advocacy Coalition Framework (ACF), de Sabatier (1987); equilibrio pontuado, como defendido por Baumgartner e Jones (2009); e o modelo desenvolvido por Richardson et al. (1999). De acordo com minha síntese, essas teorias do agendamento (agenda setting) dividem os níveis de operação em, pelo menos, três esferas separadas: desenvolvimentos sócio-históricos externos; o sistema político; e o subsistema.

Os fatores externos estão relacionados aos contextos sócio-históricos, como trajetórias demográficas (RICHARDSON et al., 1999) e os "contextos variáveis da formulação de políticas" ao longo do tempo (BAUMGARTNER; JONES, 2009, p. 54). Sabatier (1993) faz uma distinção mais precisa entre fatores externos estáveis (recursos naturais, valores éticos e socioculturais) e aspectos variáveis (opinião pública, por exemplo). Considerando-se as DHEP, os fatores externos referem-se a desenvolvimentos a longue durée da história, que na maioria das vezes estão fora de alcance dos atores.

Tanto Baumgartner e Jones (2009) quanto Sabatier (1993) fazem distinção entre um subsistema político - como o ensino superior - e o sistema político. Baumgartner e Jones (Ibid.) entendem que o sistema político é aparentemente estável, embora se altere com muita rapidez em determinados períodos. Richardson et al. (1999) o veem como parte do "ambiente político", e o subsistema como sendo descrito pelo "design do sistema". De modo geral, um subsistema concentra-se em uma área específica da política - e eu o utilizo como sinônimo para o sistema de ensino superior, ou, em outras palavras, para todas as instituições cuja ênfase reside nas políticas de ensino superior.

No modelo das DHEP, faço uma distinção entre o sistema de ensino superior e o sistema político. No caso finlandês, este último inclui todas as instituições políticas, e é considerado parte dos fatores externos do sistema de ensino superior, que inclui as instituições envolvidas nas tomadas de decisão. As três teorias do agendamento (agenda setting) têm abordagens bem semelhantes quanto à mudança dentro de um subsistema, enfatizando a relação entre as mudanças institucionais e as condições externas.

A partir de uma perspectiva de subsistema, Sabatier $(1987$; 1993) afirma que o momento oportuno pode ser uma reação a mudanças externas ou, então, o resultado de mudanças ocorridas na estrutura institucional do sistema de en- 
sino superior. Segundo a teoria do equilíbrio pontuado, a importância relativa das instituições se altera no longo prazo. As instituições afetam o escopo das agendas no sistema político (BAUMGARTNER; JONES, 2009). O elementochave da mudança é a interação entre o subsistema e seus fatores externos.

De acordo com Richardson et al. (1999, 200), a estrutura institucional pode ser alinhada aos fatores externos, mas se isso não acontecer, a mudança é quase impossível. Martinez (2002, p. 368, tradução nossa) descreve o modelo da seguinte maneira: "se a compatibilidade entre os níveis políticos estiver ausente, o resultado resume-se em conflito, frustração e impasse". Com relação à mudança na estrutura institucional, Sabatier (1993) também sustenta que a formação de coalisões dentro do subsistema, além das alterações fora dele, podem desencadear mudanças.

Para resumir os diferentes pontos de vista utilizados no desenvolvimento das DHEP, a situação política para mudança está incorporada na estrutura institucional do sistema de ensino superior e na forma como ela está alinhada aos fatores externos. Isto também explica por que as mudanças na estrutura institucional poderiam indicar o nascimento ou a morte de um kairos.

As diferentes teorias também fornecem certa orientação quanto às formas que a estrutura institucional pode assumir. De acordo com Baumgartner e Jones $(2009$, p. 32-36), as instituições criam "centros decisórios oficiais (policy venues) onde empreendedores políticos podem atuar. No entanto, também podem existir monopólios, criados para delimitar a contestação ao enfatizar a complexidade, o profissionalismo necessário ou a falta de importância social de uma determinada questão (BAUMGARTNER; JONES, 2009). Sabatier, então, apresenta a ideia da criação de coalisões de instituições ideologicamente semelhantes Em outras palavras, a estrutura institucional afeta o que pode ser politizado e quais tipos de problemas são incluídos na agenda (SABATIER, 1993; JENKINS-SMITH; SABATIER, 1993).

As diferentes teorias do agendamento (agenda setting) atraíram críticas. Kingdon (2003) afirma que o equilíbrio pontuado concentra-se demais no equilíbrio, e que as dinâmicas da mudança seriam fatores mais importante na explicação de tomadas de decisão. Martinez (2002), por sua vez, critica o modelo desenvolvido por Richardson et al. (1999) por disponibilizar pouquíssimas ferramentas para identificar como os diferentes níveis tornam-se compatíveis. Essas críticas são significativas, pois salientam que as teorias se concentram mais nos desenvolvimentos históricos, deixando a questão propriamente política de lado. Entretanto, a contribuição dessas teorias quanto à compreensão das pré-condições situacionais de mudança é vital para o desenvolvimento de um modelo teórico das dinâmicas nas políticas de ensino superior. 
Em suma, a situação política é resultado da interação entre a estrutura institucional do sistema de ensino superior, o sistema político e o contexto sócio-histórico. Caso a estrutura institucional no sistema de ensino não seja compatível com os fatores externos, a situação política é desfavorável à mudança. Para tornar a situação favorável, os atores precisam alterar a estrutura institucional ou esperar que os fatores externos mudem (Tabela 1).

\section{Possibilidades politizadas e estabelecidas}

Possibilidades políticas envolvem as diferentes alternativas que os atores identificam em diferentes situações. Possibilidades de ação estão sempre presentes, mas é uma questão de busca ativa e uso (PALONEN, 2006). A dimensão de possibilidade aprimora o modelo teórico quanto a levar em consideração a crítica que visa a dimensão de situação e fornecer ferramentas que aumentem a compreensão da mudança política. Possibilidades são criadas através da politização, da reinterpretação de algumas questões, como um conflito, ou da reorganização dos conflitos em pauta (PALONEN, 2003; 1993). Remover as possibilidades politizadas, ou despolitizá-las, é muito difícil (Id.,1993). Dentro das teorias do agendamento (agenda setting), o modelo de múltiplos fluxos (multiple streams) de Kingdon (2003) facilita a análise da politização.

A questão-chave é por que algumas questões aparecem na agenda política e por que algumas políticas tornam-se alternativas respeitáveis, enquanto outras questões e políticas acabam sendo descartadas na lata de lixo da história. Ao analisar a formação da politização, os múltiplos fluxos oferecem ideias acerca da criação das possibilidades politizadas que podem beneficiar o modelo das DHEP.

Dessa forma, o processo de agendamento (agenda setting) é explicado em termos de três fluxos diferentes: problemas, política e políticas (KINGDON, 2003). Segundo esta abordagem, os problemas são criados por diferentes indicadores que refletem a magnitude de uma condição; "eventos direcionados", tais como catástrofes ou feedback indicam problemas no sistema. Quando um problema é reconhecido, ele passa a ter potencial para ocupar uma posição na agenda política. Política refere-se a mudanças no humor nacional, mudanças de governo após as eleições ou mudanças na distribuição de cadeiras no Parlamento, enquanto as políticas lidam com as alternativas. Comunidades de especialistas e autoridades governamentais contribuem para a "sopa primordial política", uma cornucópia de soluções. Diferentes alternativas são, então, selecionadas de acordo com critérios técnicos, éticos e fiscais, bem como os interesses do público e dos políticos. (KINGDON, 2003, p. 197-201) 
A principal ideia teórica de Kingdon (2003) sobre mudanças no curso da política é a fusão dos três fluxos, trabalho de empreendedores políticos que tentam conectar dois ou mais fluxos. Quando os três fluxos estão conectados, o problema é acrescentado à agenda política, ou seja, é politizado. Uma das ideias inspiradoras de Kingdon (Ibid.) é sua abordagem não-linear para a tomada de decisão. De fato, os empreendedores políticos buscam, com mais frequência, problemas adequados a suas propostas favoritas em vez de alternativas inventadas somente após a politização ter ocorrido (BAUMGARTNER; JONES, 2009).

O modelo de Kingdon é essencial para a compreensão das diferentes formas de politização. Entretanto, de acordo com vários críticos, a abordagem de múltiplos fluxos carece de uma forte dimensão histórica (BAUMGARTNER; JONES, 2009; BAUMGARTNER et al., 2006; ZAHARIADIS, 1999). Kingdon (2003, p. 207) discute as "restrições gerais do sistema" e percorre a história no contexto de alguns casos de política, mas o ponto principal é a criação do novo espaço político em vez de dar uma perspectiva consistente sobre a história.

Outra pesquisa, todavia, indica a aparente interconexão entre o desenvolvimento histórico das instituições e a politização. Baumgartner e Jones (2009), por exemplo, analisam o papel da politização (policy images) na reformulação da estrutura institucional. A crítica sustenta que a solução das DHEP deva incluir tanto a dimensão de situação historicamente orientada quanto a dimensão de possibilidade.

Resumindo, concebo as possibilidades políticas com base no conceito de politização. No modelo das DHEP essas possibilidades podem ser tanto estabelecidas como politizadas (Tabela 1). Politização significa que os atores identificam ou criam novas possibilidades, enquanto possibilidades estabelecidas referem-se a ações de rotina realizadas de acordo com práticas preexistentes.

\section{Análise das dinâmicas através de um modelo teórico}

Dentro das duas dimensões da situação política e possibilidades políticas, o modelo teórico descreve quatro tipos diferentes de dinâmicas na política educacional, conforme apresentado na Tabela 1. Para adicionar um pouco de conteúdo empírico sobre o esqueleto teórico, as dinâmicas são exemplificadas com o caso do ensino superior finlandês (KAUKO, 2011). Como indica a Tabela 2, quatro vertentes políticas independentes são inerentes ao caso finlandês, cada uma delas ilustrando uma dinâmica. A vertente política refere-se ao desenvolvimento histórico de uma política dentro dos processos políticos do ensino superior. 
Quando estava realizando a análise, considerei primeiro o material documental e de entrevista. Como mencionado no referencial teórico, concentreime nas relações entre as instituições e identifiquei quatro vertentes políticas centrais que representam os principais aspectos das dinâmicas. Após uma nova análise do material da pesquisa, buscando regularidades e irregularidades dentro das vertentes políticas, pude construir um modelo teórico voltado para as teorias de agendamento (agenda setting). Por fim, para testar minhas considerações, procurei aspectos conflitantes no material da pesquisa e progredi na interpretação.

A primeira dinâmica é a reforma, que indica que a situação política favorece a mudança e que as possibilidades politizadas a apoiam. A vertente política da pesquisa finlandesa funciona de acordo com esta dinâmica (Tabela 2, quadrante direito inferior). A situação política finlandesa tem sido muito favorável a mudanças nas políticas de pesquisa, com ênfase em inovação. Um impulso conceitual de longo prazo rumo a um sistema nacional de inovação foi responsável por este direcionamento (MIETTINEN, 2002), e a ideia foi solidificada quando este sistema foi considerado a principal razão para a emersão da Finlândia após a depressão econômica da década de 1990. De acordo com informação verbal de um stakeholder:

\footnotetext{
Todo esse período tinha - [uma sensação], após a depressão da década de 1990, de que agora tudo era possível. A Nokia [Corporation] começou a crescer, não havia limites. Essa é a atmosfera geral de como as pessoas se sentiam (tradução nossa).
}

As mudanças na estrutura institucional deram suporte à maior ênfase em inovação. A fundação da Finnish Funding Agency for Technology and Innovation, em 1983, aumentou as oportunidades de financiamento baseado em inovação. Mais recentemente, o "superministério", sob a forma do Ministério da Economia e do Emprego, criado em 2008, teve um papel visivelmente expansivo nas políticas de inovação: "Parece que [no Ministério da Economia e do Emprego] há uma tentativa de atrelar toda as politicas educacionais e cientificas às políticas de inovação" (Stakeholder; informação verbal; tradução nossa.)

Os entrevistados também reconheceram a existência de duas coalizões de instituições na estrutura institucional: a coalizão de inovação e a coalizão de pesquisa básica. Entretanto, foram criadas possibilidades mais politizadas que favoreciam as atividades de inovação em detrimento da pesquisa básica. Isso permitiu que empreendedores políticos agissem no campo das políticas de inovação. Um bom exemplo, segundo os entrevistados, é o ex-primeiro-ministro finlandês, Esko Aho, que liderou a elaboração de uma estratégia nacio- 
nal de inovação em 2008. Ele já havia trabalhado em questões semelhantes em nível europeu, e havia certas semelhanças nas soluções sugeridas (EUROPEAN COMMISSION, 2006; TYÖ- JA ELINKEINOMINISTERIÖ, 2008; FINNISH GOVERNMENT, 2009).

Em segundo lugar, a dinâmica de impasse acontece quando existem possibilidades politizadas, mas elas se mostram inúteis porque a situação política não permite mudança (Tabela 2, quadrante esquerdo inferior). A combinação de um sistema político baseado na representação provincial, uma estrutura institucional regional de ensino superior e a pressão internacional para otimizar a estrutura criou uma situação política desfavorável ao ensino superior finlandês. Autoridades em diferentes ministérios estavam politizando possibilidades durante décadas no chamado "plano de desenvolvimento estrutural", cujo objetivo foi promover o downsizing do sistema de ensino superior (VANTTAJA; KETONEN, 1995; URSIN, VÄLIMAA; AITTOLA, 2010; 2011). Porém, tais esforços não surtiram muito efeito devido à pressão provincial sobre os políticos. De acordo informações verbais de um funcionário público:

Nós, funcionários, tínhamos sugestões de mudança e desenvolvimento que foram bloqueadas pela oposição política e, portanto, não avançaram.

A ideia de que reduziríamos os [programas de] ensino universitário, não vejo como algo possível (tradução nossa).

A terceira dinâmica, de alteração consensual, ocorre quando a situação política favorece a mudança, mas sem politização isso acontece de forma rotineira (Tabela 2, quadrante direito superior). O material da pesquisa finlandesa deixou evidente que a política internacional promovia alteração consensual. Compartilhava-se um kairos baseado na "globalização". Além disso, a estrutura institucional foi moldada para se tornar mais receptiva às influências internacionais. O Ministério da Educação e Cultura, por exemplo, integrou assuntos internacionais em suas práticas cotidianas na década de 1990. No entanto, o trabalho prático é feito por funcionários como parte de suas funções e não tanto por políticos, stakeholders ou até mesmo reitores universitários:

\footnotetext{
“O Ministério da Educação [e Cultura] tem mantido contato muito próximo com as tendências internacionais. E, muitas vezes, essas ideias e pensamentos chegaram através do ministério.” (Reitor; informação verbal; tradução nossa).
}

Os funcionários do ministério exerceram um papel relevante nas atividades internacionais. Contudo, sua forma de trabalhar transmitiu uma atitude 
pragmática nacional, implicando em possibilidades políticas estabelecidas (KAUKO, 2011). Esse tipo de pragmatismo finlandês carrega a ideia de "por que eles estão falando sobre valores e ideologias, isso é perda de tempo - não deveríamos ir direto ao assunto e ver na prática o que precisa ser feito”. (Informação verbal de funcionário público; tradução nossa)

A infiltração pragmática e seletiva de influências internacionais na elaboração das políticas nacionais teve efeitos em todas as outras vertentes políticas analisadas, já que as ideias abstratas de competição global serviram como um catalisador para a politização. A reforma da política de pesquisa foi fortemente impactada pelas percepções da importância da inovação no fortalecimento da competitividade nacional. A vertente política regional foi a mais afetada pelas ideias retiradas da análise feita pela OCDE Country Review de 2006 (OECD, 2009). Além disso, politizações anteriores inspiradas em influências internacionais, tais como a New Public Management (NPM), de meados dos anos 1980, foram incorporadas à vertente política de governança, discutida a seguir. Em suma, parece que o ambiente internacional é uma sopa primordial de políticas-chave (KINGDON, 2003), a partir do qual os empreendedores políticos - a maioria dos funcionários no caso finlandês - encontram suas soluções para apresentar na arena política nacional.

O quarto tipo de dinâmica é o atrito, que causa inércia, uma vez que a situação não é favorável à mudança e não existem possibilidades politizadas (Tabela 2, quadrante esquerdo superior). Esta dinâmica ficou evidente na política de governança, no contexto do ensino superior finlandês. A situação política deve muito às reformas da NPM. Uma situação desfavorável surgiu envolvendo a incompatibilidade entre a política e o sistema de ensino superior quando as tomadas de decisão político-estratégicas e orçamentárias foram separadas no final dos anos 1980 (TEMMES, 1996; 1998; TIILI, 2008). Por exemplo, as decisões orçamentárias em nível governamental são tomadas estritamente em conformidade com as fronteiras setoriais entre os diferentes ministérios, e a movimentação de fundos acima do limite de qualquer ministério é praticamente impossível no quadro orçamentário. Além disso, o orçamento não é coordenado com o Programa de Governo. Um funcionário criticou esta perspectiva atomística:

A elaboração do quadro orçamentário não pode começar com a leitura de cada uma das páginas do documento base. Deveríamos primeiro reservar um dia para falar sobre o assunto [como um todo]. E quando começamos no capítulo referente ao Ministério da Educação [e Cultura], deveríamos então discutir o que queremos da educação - e não começar com os números. (Funcionário público; informação verbal; tradução nossa). 
A mesma situação se aplica à contratação condicional entre o Ministério da Educação e Cultura e as universidades. Ambos consideram que o principal interesse do outro é o dinheiro, o que deixa questões políticas em segundo plano nas negociações da gestão por resultados. Nas entrevistas, os representantes do Ministério veem as universidades como interessadas apenas em dinheiro, não em políticas; e as universidades apontam uma ênfase excessiva do Ministério em questões orçamentárias ao invés de políticas:

Por exemplo, esses objetivos comuns que preparamos detalhadamente aqui [no Ministério da Educação e Cultura] - - a gestão das universidades raramente tem algo a dizer. (Funcionário público; informação verbal; tradução nossa).

\begin{abstract}
Mas então eles [o Ministério da Educação e Cultura] anunciaram quase que sem rodeios que essas metas de graduação [que são a base para o financiamento] são definidas de maneira que todas as universidades possam sobreviver. - - Não foi dada atenção ao nível de pesquisa em uma determinada área de formação ou em uma determinada universidade - (Reitor; Informação verbal; tradução nossa).
\end{abstract}

A dinâmica de atrito, devido à separação dos meios orçamentários e fins políticos na vertente política de governança, restringe outras políticas. $\mathrm{O}$ impasse na vertente política regional foi ainda mais acentuado. A pressão orçamentária para abolir unidades de ensino superior foi compreendida, mas, em termos de política regional, era algo impossível de implementar. Houve um fenômeno semelhante nas políticas de pesquisa, pois o influente órgão político - o Conselho de Pesquisa e Inovação, que abriga inúmeros ministros - raramente recebia apoio financeiro integral do governo. "Ele toma decisões sobre para onde o dinheiro deve ser canalizado, o que às vezes se concretiza, outras, não." (Político; informação verbal; tradução nossa). Em suma, não havia oportunidades para desenvolver uma visão holística, porque as discussões políticas e orçamentárias não ocorriam na mesma mesa, ao mesmo tempo.

Dois monopólios contribuíram para a falta de politização das vertentes políticas internacional e governamental. No primeiro caso, o Ministério da Educação foi o principal responsável por filtrar tendências internacionais através de suas conexões com a OCDE e da UE, enquanto que, no último, o Ministério das Finanças tinha um monopólio para iniciar reformas de governança e também fazer os primeiros esboços dos quadros orçamentários. 
Parece, portanto, que as vertentes políticas nas dinâmicas de alteração consensual e de atrito influenciaram todo o sistema. Por um lado, a alteração consensual nas políticas internacionais deu um impulso às politizações em outras vertentes políticas. Por outro lado, o atrito na política de governança também protelou outras vertentes. Os resultados empíricos sugerem que os aspectos não discutidos - ou seja, que não são politizados - são na verdade os mais influentes.

\section{Um novo modelo para pesquisa de ensino superior em contextos contin- gentes}

A ênfase nas inter-relações entre instituições pareceu dar um embasamento consistente para as DHEP e o exemplo empírico da Finlândia. O caso finlandês confirmou os pressupostos de pesquisas anteriores sobre dinâmicas. Com base nos resultados, é possível identificar que as dinâmicas nas políticas de ensino superior estão fortemente relacionadas a mudanças externas ao sistema de ensino superior, às posições varáveis das instituições ou atores em diferentes vertentes políticas e à natureza inesperada das dinâmicas.

Pesquisas anteriores identificaram os fatores externos de um sistema de ensino superior como uma das principais razões para a mudança (KOGAN et al., 2000; RICHARDSON et al., 1999; SABATIER, 1993). A dimensão teórica da situação política poderia facilitar uma conceitualização mais precisa dessa mudança. Uma situação favorável necessita que pelo menos três aspectos sejam coerentes: as principais trajetórias na história (em outras palavras, o contexto sócio-histórico); o sistema político (que tem que possibilitar mudanças); e a estrutura institucional do sistema de ensino superior (que tem que ser receptiva a mudanças). De acordo com o modelo das DHEP, mudanças em cada um destes aspectos podem estimular ou prejudicar uma situação política favorável, um kairos. Além disso, o curso da mudança é determinado pelas possibilidades politizadas ou estabelecidas.

Nesta análise, tratar as universidades da mesma forma que outras instituições mostrou-se produtivo, como sugerido em pesquisas anteriores (SAARINEN; VÄLIMAA, 2006; FERLIE; MUSSELIN;ANDRESANI, 2008; FRACKMANN, 1992). Não sugiro que o papel acadêmico das universidades possa impactar quaisquer dinâmicas no sistema. A dinâmica de atrito mais influente, por exemplo, não tinha nenhuma relação com características acadêmicas. O fato de não ter sido tomado o caráter único das universidades como ponto de partida possibilitou a concentração desta pesquisa em múltiplas instituições e a análise do sistema de ensino superior finlandês com uma abordagem mais holística. 
Pesquisas anteriores, que se concentram nas dinâmicas ignoram considerações de política arquitetural e aceitam a diferença e fluidez nas posições das instituições (OLSEN, 2007; VÄLIMAA, 2005; BLEIKLIE et al., 2000). O modelo das DHEP mostrou-se promissor quanto à compreensão das mudanças destas posições. As quatro dinâmicas distintas dizem respeito às mesmas instituições, mas seus papéis são bem diferentes. Enquanto o Ministério da Educação e Cultura foi fundamental na transmissão consensual de influências internacionais, ele era ineficaz nas políticas regionais mais controversas, por exemplo. Isto também se traduz em crítica à concepção estática sobre política, que se concentra nos atributos dos atores: as mesmas instituições variam quanto ao seu peso político dependendo das dinâmicas que se manifestam na vertente política.

A natureza inesperada das políticas é reconhecida em pesquisas anteriores sobre dinâmicas com base na ideia dominante de contingência. Em termos analíticos, isto significa que mudanças na situação política e a politização de possibilidades geram um resultado inesperado. Até o momento, não se havia destacado a análise dos aspectos implícitos e restritivos das políticas de ensino superior. Välimaa (2005), por exemplo, analisa diferentes conflitos politizados e explícitos no decurso do ensino superior finlandês. E, ainda mais importante, as DHEP também podem ser usadas para elucidar os efeitos das possibilidades estabelecidas que podem viabilizar ou impossibilitar outras vertentes políticas.

$\mathrm{Na}$ minha perspectiva, existem três grandes projetos que podem desenvolver ainda mais as DHEP: ampliá-la, para incluir táticas políticas; refiná-la, para usá-la em educação comparada; e analisar dinâmicas em outras áreas políticas. A análise de táticas políticas poderia partir da dimensão play \& game de contingência (PALONEN, 2006), com foco na ação em nível micro e baseando-se em etnografia ou entrevistas em profundidade. Em termos de pesquisa comparativa, as DHEP têm o potencial de superar o desafio de desenvolver uma comparação mais baseada na história e consciente da sociedade (KAUKO et al., 2012; NÓVOA; YARIV-MASHAL, 2003). A ampliação do modelo para outras áreas políticas poderia iniciar no campo da educação obrigatória: há indícios de dinâmicas semelhantes no caso finlandês, por exemplo (SIMOLA; VARJO; RINNE, 2011; SIMOLA et al. 2009). No entanto, o desenvolvimento mais interessante seria aprimorar o modelo, descobrindo mais dinâmicas. Para tanto, é necessário realizar mais trabalhos empíricos e este tema continua sendo uma oportunidade de pesquisa futura a ser abordada. 
Tabela 1. Um modelo teórico para analisar as dinâmicas nas políticas de ensino superior (DHEP)

\begin{tabular}{|c|c|c|}
\hline & $\begin{array}{c}\text { A situaçáo política é des- } \\
\text { favorável à mudança }\end{array}$ & $\begin{array}{c}\text { A situação } \\
\text { política é } \\
\text { favorável à } \\
\text { mudança }\end{array}$ \\
\hline $\begin{array}{c}\text { As possibilidades politicas } \\
\text { são estabelecidas }\end{array}$ & Dinâmica de atrito & $\begin{array}{c}\text { Dinâmica } \\
\text { de alteração } \\
\text { consensual }\end{array}$ \\
\hline $\begin{array}{c}\text { As possibilidades políticas } \\
\text { são politizadas }\end{array}$ & Dinâmica de impasse & $\begin{array}{c}\text { Dinâmica de } \\
\text { reforma }\end{array}$ \\
\hline
\end{tabular}

Fonte: Kauko (2011)

Tabela 2. Dinâmicas nas políticas de ensino superior e vertentes políticas finlandesas

\begin{tabular}{|c|c|c|}
\hline & $\begin{array}{c}\text { A situação política é des- } \\
\text { favorável à mudança }\end{array}$ & $\begin{array}{c}\text { A situação po- } \\
\text { litica é favorá- } \\
\text { vel à mudança }\end{array}$ \\
\hline $\begin{array}{c}\text { As possibilidades políticas } \\
\text { são estabelecidas }\end{array}$ & $\begin{array}{c}\text { Dinâmica de atrito na } \\
\text { vertente política de go- } \\
\text { vernança }\end{array}$ & $\begin{array}{c}\text { Dinâmica de } \\
\text { alteração con- } \\
\text { sensual na ver- } \\
\text { tente política } \\
\text { internacional }\end{array}$ \\
\hline $\begin{array}{c}\text { As possibilidades políticas } \\
\text { são politizadas }\end{array}$ & $\begin{array}{c}\text { Dinâmica de impasse na } \\
\text { vertente política regional }\end{array}$ & $\begin{array}{c}\text { Dinâmica de } \\
\text { reforma na } \\
\text { vertente políti- } \\
\text { ca de pesquisa }\end{array}$ \\
\hline
\end{tabular}

Fonte: Kauko (2011) 


\section{Referências}

BAUMGARTNER, Frank R.; GREEN-PEDERSEN, Christoffer; JONES, Bryan D. Comparative studies of policy agendas. Journal of European Public Policy, [S.1.], v. 13, n. 7., p. 959-974. 2009.

BAUMGARTNER, F. R.; JONES, B. D. Agendas and instability in American politics. 2a ed. Chicago, IL: Chicago University Press. 2006. 298p.

BLEIKLIE, Ivar. Policy Regimes and Policy Making. In: KOGAN, Maurice; BAUER, Marianne; BLEIKLIE, Ivar; HENKEL, Mary (Eds.) Transforming Higher Education. A Comparative Study London: Jessica Kingsley. 2000, p. 53-87.

BLEIKLIE, Ivar; HØSTAKER, ROAR; VABØ, AGNETE. Policy and Practice in Higher Education. Reforming Norwegian Universities. London: Jessica Kingsley. 2000. 350p. (Higher Education Policy Series 49).

BOER, H. de; ENDERS, J.; SCHIMANCK, U. Comparing Higher Education Governance Systems in Four European Countries. In: SOGUEL, Nils C.; JACCARD, Pierre (Eds.) Governance and Performance of Education Systems. Dordrecht: Springer. 2007, p. 34-54.

CERYCH, Ladislav; SABATIER, Paul. Great Expectations and Mixed Performance: The Implementation of Higher Education Reforms in Europe. Trentham: Trentham Books. 1986. 276p.

CLARK, Burton R. The Problem of Complexity in Modern Higher Education [Originally 1993]. In: CLARK, Burton R. On Higher Education. Selected Writings, 1956-2006, Baltimore, MD: The Johns Hopkins University Press, 2008, p.385-404.

CORBETT, Anne Universities and the Europe of Knowledge. Ideas, Institutions and Policy Entrepreneurship in European Union Higher Education Policy, 1955-2005. Basingstoke: Palgrave Macmillan. 2005. 268p.

EMIRBAYER, Mustafa. Manifesto for a Relational Sociology. The American Journal of Sociology, [S.1.], v.103, n.2, p.281-317, 1997.

EUROPEAN COMMISSION. Creating an Innovative Europe. Report of the Independent Expert Group on R\&D and Innovation appointed following the Hampton Court Summit and chaired by Mr. Esko Aho. Luxembourg: European Communities, Jan.,2006. Disponível em: $<$ http:// ec.europa.eu/invest-in-research/pdf/download_en/aho_report.pdf > Acesso em: 9 nov. 2011.

FERLIE, Ewan; MUSSELIN, Christine;ANDRESANI, Gianluca. The steering of higher education systems: a public management perspective. Higher Education, [S.1.], v.56 n.3, p.325348, Apr.,2008.

FINNISH GOVERNMENT. Governments Communication on Finland's National Innovation Strategy to the Parliament, 2009. Disponível em: <http://www.tem.fi/files/21010/National_Innovation_Strategy_March_2009.pdf>. Acesso em: 9 nov. 2011.

FRACKMANN, Edgar. The Role of Buffer Institutions in Higher Education. Higher Education Policy, [S.1.], v. 5, n.3, p.14-17, 1992. 
GORNIZKA, Åse, MAASSEN, Peter, OLSEN, Johan P.; STENSAKER, Bjørn. Europe of Knowledge: Search for a New Pact. In: MAASSEN, Peter. ; OLSEN, Johan P. (Eds..) University Dynamics and European Integration. Dordrecht: Springer, 2007, p.181-214.

GREEK ANTHOLOGY. [Trans. W.R. Paton]. Vol. V. London: Willian Heinemann; NY: G.P. Putnam's Sons. [1918]. Disponível em: <http://www.archive.org/stream/greekanthology05newyuoft> Acesso em: 9 nov. 2011.

JENKINS-SMITH, Hans C.; SABATIER, Paul A. The Study of Public Policy Processes. In: SABATIER, Paul A. ;JENKINS-SMITH, H. C. (Eds..) Policy Change and Learning. An Advocacy Coalition Approach. Boulder, CO: Westview Press, 1993, p.1-9.

KAUKO, Jaakko. Korkeakoulupolitiikan dynamiikat Suomessa [Dynamics of Higher Education Politics in Finland]. Helsinki: University of Helsinki, Department of Behavioural Sciences, 2011. Disponível em: <http://urn.fi/URN:ISBN:978-952-10-6984-0> Acesso em: 9 nov. 2011.

KAUKO, Jaakko; SIMOLA, Hannu; VARJO, Janne.; KALALAHTI, Mira What could a dynamics perspective contribute to comparative research? In: KIVIRAUMA, Joel; JAUHIANEN, Arto, SEPPÄNEN, Piia; KAUNISTO, Tuuli (Eds..) Koulutuksen yhteiskunnallinen ymmärrys. Social Perspectives on Education. Research in Educational Sciences. Turku: Finnish Educational Research Association, 2012, p.219-233.

KINGDON, John W. Agendas, Alternatives, and Public Policies. 2nd ed. New York: Longman. 2003. 253p.

KOGAN, Maurice; HANNEY, S. Reforming Higher Education. London: Jessica Kingsley, 2000 .

KOGAN, Maurice, BAUER, Marianne, BLEIKLIE, Ivar; HENKEL, Mary. Change and Continuity. Some Conclusions. In: KOGAN. M. \& HANNEY, S. (Eds.). Reforming Higher Education. London: Jessica Kingsley, 2000, p.199-214.

MARTINEZ, Mario C. Understanding State Higher Education Systems. Applying a New Framework. The Journal of Higher Education, [S.1.], v.73, n. 3, p. 349-374, 2002.

MAYNTZ, Renate; SCHARPF, Fritz W. Der Ansatz des akteurzentrierten Institutionalismus [The actor-centred approach to institutionalism] In: MAYNTZ, Renate; SCHARPF, Fritz W. (Eds..) Gesellschaftliche Selbstregelung und politische Steuerung [Societal self-regulation and political steering], Frankfurt: A.M.; New York, NY: Campus Verlag. 1995, p.39-72.

MIETTINEN, Reijo. National Innovation System. Scientific Concept or Political Rhetoric. Helsinki: Edita. 2002. 168 p.

MEISTER-SCHEYTT, Claudia; SCHEYTT, Tobias. The Complexity of Change in Universities. Higher Education Quarterly, [S.1.],v.59, n.1, p.76-99, 2005.

METCALFE, Amy S. Theorizing Research Policy: A Framework for Higher Education. In: SMART, John C. (Eds.) Higher Education: Handbook of Theory and Research. Dordrecht: Springer. 2008, p.241-275.

MILLS, Michael R. Stories of Politics and Policy: Florida's Higher Education Governance Reorganization. The Journal of Higher Education, [S.1.], v. 78, n. 2, p.162-187, 2007. 
NEAVE, Guy. On Bodies vile and Bodies Beautiful: the Role of 'Buffer' Institutions Between Universities and State. Higher Education Policy, [S.1.], v.5, n. 3, p. 10-17, 1992.

NÓVOA, António; YARIV-MASHAL, T. Comparative Research in Education: a mode of governance or a historical journey? Comparative Education, [S.1.], v. 39, n.4, p.423-439, 2003.

OECD. OECD Reviews for Tertiary Education. Finland. [Written by John Davies, Thomas Weko, Lillemor Kim and Erik Thulstrup.]. S.1., OECD, 2009. Disponível em: $<$ https://www. oecd.org/education/skills-beyond-school/37474463.pdf> Acesso em: ?

OLSEN, Johan P. The Institutional Dynamics. In: MAASSEN, P. ; OLSEN, Johan P. (Eds..) University Dynamics and European Integration, Dordrecht: Springer. 2007, p. 25-34.

OSTROM, Elinor. Understanding Institutional Diversity. Princeton, NJ: Princeton University Press. 2005. 355p.

PALONEN, Kari. Introduction: from policy and polity to politicking and politicization. In: PALONEN, Kari; PARVIKKO, Tuija (Eds.) Reading the Political: Exploring the Margins of Politics. Helsinki: The Finnish Political Science Association. 1993, p.6-16.

PALONEN, K. Four Times of Politics: Policy, Polity, Politicking, and Politicization. Alternatives, [S.1.], v.28, n.2, p.171-186, 2003.

. The Struggle with Time. A Conceptual History of 'Politics' as an Activity. Hamburg: Verlag Münster, 2006.

.Politics or the political? A historical perspective on a contemporary non-debate. Europe-

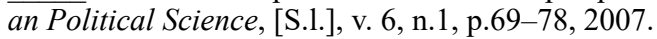

PIERSON, Paul. Politics in Time. History, Institutions, and Social Analysis. Princeton \& Oxford: Princeton University Press, 2004. 196p.

RICHARDSON, Richard C.; BRACCO, Kathy R.; CALLAN, Patrick M.; FINNEY, Joni E. Designing State Higher Education Systems for a New Century. Phoenix, AZ: The Oryx Press. 1999. 219p.

SAARINEN, Taina. Quality on the move. Discursive Construction of Higher Education Policy from the Perspective of Quality. Jyväskylä studies in humanities, 83. Jyväskylä: University of Jyväskylä. 2007. Disponível em: <https://jyx.jyu.fi/dspace/bitstream/handle/123456789/13445/9789513930431.pdf?sequence=1> Acesso em: 9 nov. 2011.

SAARINEN, Taina; VÄLIMAA, Jussi. Muutos korkeakoulupolitiikan tutkimuksessa. [Change in higher education studies.] In: URSIN, Jani; VÄLIMAA, Jussi (Eds.) Korkeakoulutus teorias$s a$ [Higher education in theory] Jyväskylä: Koulutuksen tutkimuslaitos, Jyväskylän yliopisto, 2006, p.91-111.

SABATIER, Paul A. Knowledge, Policy-Oriented Learning, and Policy Change. An Advocacy Coalition Framework. Knowledge: Creation, Diffusion, Utilization, [S.1.], v.8, n.4, p.649-692, 1987.

Policy Change over a Decade or More. In: SABATIER, Paul A.; JENKINS-SMITH,

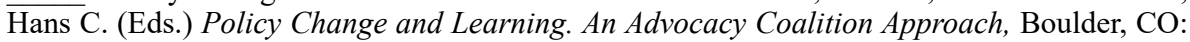
Westview Press, 1993, p.13-39. 
SCHARPF, Fritz W. Games Real Actors Play: Actor-Centered Institutionalism in Policy Research. Boulder, CO: Westview Press, 1997. 318p.

SABATIER, Paul A. From Policy Implementation to Policy Change: A Personal Odyssey. In: GORNITZKA, Åse, KOGAN, Maurice; AMARAL, Alberto. (Eds..). Reform and Change in Higher Education. Dordrecht: Springer, 2005, p.17-34.

SCOTT, Richard W. Institutions and Organizations. $3^{\text {rd }}$ ed. Thousand Oaks, CA: Sage, 2008. $266 \mathrm{p}$.

SIMOLA, Hannu; RINNE, Risto; VARJO, Janne; PITKÄNEN, Hannele; KAUKO, Jaakko. Quality assurance and evaluation (QAE) in Finnish compulsory schooling: a national model or just unintended effects of radical decentralization? Journal of Education Policy, [S.1.], v. 24, n.2, p.163-178, 2009.

SIMOLA, Hannu; VARJO, Janne; RINNE, Risto. À contre-courant: dépendance au sentier, convergence et contingence. Vers une meilleure compréhension du modèle finlandais d'assurance-qualité et d'évaluation. [Against the Flow - Path dependence, convergence and contingency in understanding the Finnish QAE model]. Éducation et Sociétés: Revue internationale de sociologie de l'éducation, v.28, n.2, p.35-51, 2011.

SLAUGHTER, Sheila; RHOADES, Gary. From "Endless Frontier" to "Basic Science for Use": Social Contracts between Science and Society. Science, Technology \& Human Values, [S.1.], v. 30, n. 4, p. 36-572, 2005.

TEMMES, Markku. Hallintopolitiikan rakennedoktriinit [The structural doctrines in governance policy]. Hallinnon tutkimus, [S.1.], v. 15, n. 2, p.90-109, 1996.

. Finland and New Public Management. International Review of Administrative Sciences, [S.1.], v. 64, n.3, p.441-456, 1998.

TIILI, Minna. Ministers as strategic political leaders? Strategic political steering after NPM reforms in Finland. Acta Politica 34. Helsinki: Department of Political Science, University of Helsinki, 2008.

TYÖ- JA ELINKEINOMINISTERIÖ. Kansallinen innovaatiostrategia. Helsinki: Työ- ja elinkeinoministeriö, 2008.

URSIN, Jani; SAARINEN, Taina. Dominant and emerging approaches in the study of higher education policy change. Studies in Higher Education, [S.1.], v.37, n. 2, p.143-156, 2012.

URSIN, Jani; VÄLIMAA, Jussi; AITTOLA, Helena. Towards Joint Educational Structures and Practices. Experiences From The Mergers of Finnish Universities. In: EERA-CONFERENCE, 25, Helsinque, Annals... EERA, Aug. 2010.

. Yliopistot yhdistyvät - muuttuuko koulutus? [Universities merge - does education change?] In: RINNE, Rinne; JAUHIAINEN, Arto, TÄHTINEN, Juhani; BROBERG, Mari. (Eds.) Koulutuspolitiikan käytännöt kansallisessa ja ylikansallisessa kehyksessä [Practises of education politics in national and international frames. Kasvatusalan tutkimuksia 54. Turku: Suomen kasvatustieteellinen seura, 2011, p.125-144.

VANTTAJA, Markku; KETONEN, Kimmo Korkeakoululaitoksen rakenteellinen kehittäminen. Tapaustutkimus lääketieteen ja kasvatustieteen koulutusaloilta. [The structural develop- 
ment of higher education system. A case study on the disciplines of medicine and education.] Koulutussosiologian tutkimuskeskuksen raportteja 28. Turku: University of Turku, 1995.

VÄLIMAA, Jussi. Social Dynamics of Higher Education Reforms: The Case of Finland. In: GORNITZKA, Åse; KOGAN, Maurice; AMARAL, Alberto. (Eds.), Reform and Change in Higher Education. Analysing Policy Implementation. Dordrecht: Springer, 2005, p.245-268.

VÄLIMAA, Jussi.; HOFFMAN, David. Knowledge society discourse and higher education. Higher Education, [S.1.], v.56, p. 265-285, 2008.

ZAHARIADIS, Nikolaos. Ambiguity, Time, and Multiple Streams. In: SABATIER, Paul A. (Ed.) Theories of the Policy Process, Boulder, CO: Westview Press, 1999, p.73-93.

\section{Agadecimento}

Copyright com a devida permissão de Springer Science+Business Media: Higher Education, Dynamics in Higher Education Politics: a Theoretical Model, vol. 65 (2), 2013, Jaakko Kauko.

Submissão em: 17/06/2015

Aceite em: 06/04/2016

Agência de fomento: Academy of Finland

Jaakko Kauko é PhD, Associate Professor na Faculdade de Educação da Universidade de Tampere, Livre-Docente no Instituto de Ciências Comportamentais da Universidade de Helsinque, coordenador de um grupo de pesquisa no Centro de Excelência Nórdico "Justiça via educação nos países nórdicos" (www.helsinki.fi/ justed) e pesquisador principal no projeto de pesquisa "Dinâmicas transnacionais nas políticas de Qualidade e Avaliação na Educação Básica no Brasil, na China e na Rússia" (2014-2017). Endereço para correspondência: Institute of Behavioural Sciences, Siltavuorenpenger $1 \mathrm{~A}$ University of Helsinki, 00014 Helsinki, Finland E-mail: jaakko.kauko@,helsinki.fi 